\title{
Diagnosis and Antimicrobial Susceptibility of Mycobacterium Tuberculosis in a Tertiary Care Hospital in Bangladesh
}

\author{
Mostofa Showkat Imran ${ }^{*}$, Amitav Sahaㄹ, Faruque Ahmed ${ }^{3}$, Masudur Rahman ${ }^{4}$, S.M. Mostafa \\ Kamal $^{5}$, Golam Kibria ${ }^{6}$, Md. Shamim Hossain ${ }^{7}$
}

1Assistant Professor, Department of Gastroenterology, Ibn Sina Medical College, Dhaka, Bangladesh.

Email ID: imranssmc@gmail.com

Orcid ID: 0000-0001-5151-4237,

2Assistant Professor, Department of Gastroenterology, Dhaka Medical College Hospital, Dhaka, Bangladesh.

Email ID: imranssmc@gmail.com

Orcid ID: 0000-0001-5151-4237

3Professor \& Project Director, Sheikh Russel Gastro liver Institute \& Hospital, Mohakhali, Dhaka, Bangladesh.

Email ID: imranssmc@gmail.com

Orcid ID: 0000-0001-5151-4237,

4Associate Professor, Department of Gastroenterology, Sheikh Russel Gastro liver Institute \& Hospital, Mohakhali, Dhaka, Bangladesh.

Email ID: imranssmc@gmail.com

Orcid ID: 0000-0001-5151-4237

5Professor \& Head, Department of Microbiology, Anwer Khan Modern Medical College and Hospital, Dhaka, Bangladesh.

Email ID: imranssmc@gmail.com

Orcid ID: 0000-0001-5151-4237,

${ }^{6}$ Associate Professor \& Joint Director, Sheikh Russel Gastro liver Institute \& Hospital, Mohakhali, Dhaka, Bangladesh. Email ID: imranssmc@gmail.com

Orcid ID: 0000-0001-5151-4237

${ }^{7}$ Medical Techlogist(Lab), Institute of Public Health Nutrition, Mohakhali, Dhaka, Bangladesh.

Email ID: imranssmc@gmail.com

Orcid ID: 0000-0001-5151-4237,

${ }^{*}$ Corresponding author

Received: 05 December 2022

Revised: 03 January 2022

Accepted: 14 January 2022

Published: 18 February 2022

\section{Abstract}

Background: Tuberculosis (TB) is a common condition all over the world but more common in developing countries like Bangladesh38. This is second only to HIV/ AIDS as the greatest killer worldwide due to a single infectious agent. In 2013, 9 million people fell ill with TB and 1.5 million died from the disease globally. Approximately $15-20 \%$ of total TB cases are extrapulmonary in nonHIV patients. Among extrapulmonary TB, abdominal tuberculosis (ATB) accounts for $11 \%-16 \%$. Abdominal TB is difficult to diagnose because of its lack of specific symptoms, low yield of acid-fast bacilli (AFB) on smear and culture due to paucibacillary lesion; and variable manifestations depending upon anatomical localization of the disease. The diagnosis of abdominal TB classically requires histopathological, microbiological and culture confirmation of Mycobacterium tuberculosis. Investigations like Imaging (Ultrasound, Barium X-Rays, and CT scan) and the Mantoux test have only supportive value. Aim of the study: The aim of the study was to diagnose modalities and antimicrobial susceptibility in abdominal tuberculosis patients. Material \& Methods: This cross-sectional hospital-based observational study was carried out among 73 adult patients with the diagnosis of abdominal TB who met the selection criteria and attended in Gastroenterology department of DMCH through either admission or referral from May 2015 to April 2016. Results: The most frequent symptoms were weight loss $(96.9 \%)$, abdominal pain $(75 \%)$, and fever $(75 \%)$. The most frequent signs were anaemia $(34.4 \%)$, followed by ascites $(27.9 \%)$. Basis of diagnosis in abdominal tuberculosis was histolopathogy in $37.5 \%$, Gene Xpert in $28.1 \%$, Positive AFB on culture in $9.4 \%$, ADA value in ascitic fluid (Cutoff $>40 \mathrm{IU} / \mathrm{L}$ ) in $25 \%$, and good clinical response (Based on weight gain and general improvement in wellbeing) to a therapeutic trial of anti-TB treatment in $18.7 \%$ patients. Drug sensitivity pattern was analyzed in all three AFB culture-positive patients; resistance was detected in one which showed multidrug resistance (MDR TB). Conclusions: The result of this study highlighted the diagnostic yield of various investigation modalities, particularly newer modalities (Gene Xpert, culture sensitivity in Bactec MGIT 960) and basis of diagnosis in abdominal TB. This study also determined the MTB culture positivity from tissue biopsies in patients with abdominal TB and demonstrated drug-resistant MTB in culture-confirmed abdominal TB. 
Annals of International Medical and Dental Research

E-ISSN: 2395-2822 | P-ISSN: 2395-2814

Vol-8, Issue-2 | March-April 2022

DOI: 10.53339/aimdr.2022.8.2.17

Page no- 120-127 | Section- Research Article (Gastroenterology)

Keywords:- Abdominal Tuberculosis, Susceptibility, Multidrug resistance.

\section{INTRODUCTION}

Tuberculosis is a disease that has plagued humanity for millennia. There are an estimated 7.5 million cases of tuberculosis in the global population, with 2.5 million fatalities every year, making tuberculosis the leading cause of infection-related death behind HIV/AIDS. [1] Antimicrobial resistance in Mycobacterium tuberculosis, both primary and acquired, is a worldwide concern. $[2,3,4]$ It is still a serious public health issue in Bangladesh, $[1]$ and the rapid growth of drug-resistant mycobacteria has increased the necessity for quick detection and efficient treatment. MDR (multidrugresistant) strains are becoming more common. Laboratories must provide prompt diagnosis and efficient antimicrobial susceptibility testing (AST) for effective illness treatment. [5,6] Though the BACTEC 460TB technique (Becton Dickinson Co., Towson, MD) is a wellestablished, semi-automated, broth-based method for fast detecting mycobacteria within a closed system, this system detects mycobacterial growth using a radiometric method. The disposal of radioactive waste generated by the BACTEC 460TB method presents a significant logistical challenge and increased costs. [7] The essential medications in treating tuberculosis are rifampin (RIF) and isoniazid (INH), and resistance to these antibiotics often incurable tuberculosis. ${ }^{[8]}$ Due to the lengthy turnaround time for standard susceptibility testing, patients infected with drug-resistant tuberculosis may receive poor treatment, allowing resistant strains to spread. [9] It takes 6-9 weeks to diagnose tuberculosis in the lab and then test the isolated bacterium for treatment resistance using standard procedures. [10,11,12] Simultaneously, quick drug resistance evaluation is critical for selecting effective pharmacological therapy and avoiding the spread of drug-resistant strains. As a result, a tuberculosis control program faces the issue of developing new quick methods for evaluating medication resistance. Mutations in an 81-bp region of the rpoB gene encoding the beta subunit of RNA polymerase (rifampin resistance-determining region [RRDR]) cause RIF resistance in Mycobacterium tuberculosis strains collected around the world. $[13,14,15]$ Early detection and treatment of patients and contacts are critical for the success of control strategies. Patients may fail to respond to anti-tubercular therapy for various reasons, one of which is medication resistance, which is becoming increasingly common in both developed and developing countries.[16,17,18,19] Different methods for assessing drug susceptibility of tubercle bacilli have been employed in the past, with the proportion approach using Lowenstein-Jensen (L-J) medium being the most frequently acknowledged.[20] E test, bioluminescence, polymerase chain reactionsingle strand conformational polymorphism (PCR-SSCP), and other nontraditional procedures are utilized in many laboratories. Non-uniformity and lack of standardization of laboratory processes, which is also a significant issue, may impede the accurate assessment of drug resistance, resulting in misleading data and hence a lack of understanding of the true incidence of drug resistance.[21] It would be ideal to have a simple, quick, and consistent 
Annals of International Medical and Dental Research

E-ISSN: 2395-2822 | P-ISSN: 2395-2814

Vol-8, Issue-2 | March-April 2022

DOI: 10.53339/aimdr.2022.8.2.17

Page no- 120-127 | Section- Research Article (Gastroenterology)

approach for determining drug susceptibility that does not require expensive equipment. Antimicrobial resistance must be detected quickly if the spread of resistant Mycobacterium TB is to be controlled. The results of various inquiry methodologies for tuberculosis diagnosis vary.[22] Smear and culture yields of organisms in the ascitic fluid are minimal. In less than $3 \%$ of cases, acid fast bacilli staining is positive. In less than $20 \%$ of cases, a positive culture is obtained.[23] The activity of adenosine deaminase (ADA) in ascitic fluid is a sensitive and specific indicator of tuberculosis. [24] Because ADA is found in Tlymphocytes and macrophages, its levels rise in response to T-lymphocyte stimulation by CMI to mycobacterial antigens. [25] According to a study, sensitivity was 100 percent, and specificity was 96 percent when the cutoff value of 40U/L was used.[1] Endoscopic biopsy has a diagnostic yield of between 30 and 80 percent $>$.26] In a study of 61 patients with abdominal TB in Mumbai, India, histology was used to diagnose $78.6 \%$ of the cases.[27] In a study of 209 patients with abdominal TB in Pakistan, histopathology was analyzed in $42 \%$ of the cases. [22]

\section{Objectives}

To diagnose the suspected cases of abdominal tuberculosis patients.

\section{MATERIAL AND METHODS}

\section{Type of study}

This is an observational prospective clinical study.

\section{Place and period of study}

This study was conducted in the Gastroenterology department of Dhaka Medical College Hospital (DMCH) in collaboration with National Tuberculosis Reference Laboratory, NIDCH, Mohakhali, Dhaka from May 2015 to April 2016.

\section{Study population}

Patients diagnosed with abdominal tuberculosis (based on positive AFB culture, Gene Xpert, histopathology, ascitic fluid ADA report, and response to anti-TB trial) attended in the Gastroenterology department of $\mathrm{DMCH}$ through admission or referral.

\section{Inclusion criteria}

- Abdominal tuberculosis patients

- Admitted or referred patients

- Age-any adult patient

\section{Sample selection}

A total of 73 patients who attended the Gastroenterology department of DMCH either through admission or referral for May 2015 to April 2016were selected considering the inclusion criteria.

\section{Statistical data analysis}

The statistical analysis was performed using MS Excel 2016 and statistical package for social sciences (SPSS) version 25.0 for Windows (SPSS, Chicago IL, USA). The data of categorical variables are presented as frequencies and percentages. 
Annals of International Medical and Dental Research

E-ISSN: 2395-2822 | P-ISSN: 2395-2814

Vol-8, Issue-2 | March-April 2022

DOI: 10.53339/aimdr.2022.8.2.17

Page no- 120-127 | Section- Research Article (Gastroenterology)

\section{RESULTS}

Table 1 shows the frequency distribution of the signs and symptomsof abdominal tuberculosis in a Tertiary Care Hospital in Bangladesh with a percentage rate. According to patients' data, most people lost their weight, close to $97 \%$. Maximum patients (75\%) had abdominal pain and severe fever symptoms. Loss of appetite (68.8\%) and night sweats $(34.4 \%)$ aresignificant symptoms of the people of this research. Onefourth of the respondents (25\%) had diarrhoea, alteration of bowel habits, and
constipation.Only a tiny proportion of the patients faced vomiting, and the amount was $15.6 \%$.

This distributive table also indicates the most frequent signs of abdominal tuberculosis patients. Maximum patients had the problems of anemia (35\%), ascites $(27.9 \%)$, and mass in the right lower quadrant $(18.8 \%)$. A few of the respondents encountered abdominal lymphadenopathy $(9.3 \%)$, oedema $(6.3 \%)$, and hepatomegaly $(6.3 \%)$.

Table 1: Most frequent signs and symptoms of abdominal tuberculosis in a Tertiary Care Hospital in Bangladesh

\begin{tabular}{|c|c|c|c|c|c|}
\hline Symptoms & Frequency & Percentage & Signs & Frequency & Percentage \\
\hline Weight loss & 70 & $96.9 \%$ & Anemia & 25 & $34.4 \%$ \\
\hline $\begin{array}{l}\text { Abdominal pain } \\
\text { and fever }\end{array}$ & 54 & $75 \%$ & Ascites & 20 & $27.9 \%$ \\
\hline Loss of appetite & 50 & $68.8 \%$ & $\begin{array}{l}\text { Mass in the right } \\
\text { lower quadrant }\end{array}$ & 14 & $18.8 \%$ \\
\hline Night sweats & 25 & $34.4 \%$ & $\begin{array}{l}\text { Distension } \\
\text { abdomen }\end{array}$ & 9 & $12.6 \%$ \\
\hline $\begin{array}{l}\text { Diarrhoea and } \\
\text { bowel habit change }\end{array}$ & 18 & $25 \%$ & $\begin{array}{l}\text { Abdominal } \\
\text { lymphadenopathy }\end{array}$ & 7 & $9.3 \%$ \\
\hline Constipation & 18 & $25 \%$ & Oedema & 5 & $6.3 \%$ \\
\hline Vomiting & 12 & $15.6 \%$ & Hepatomegaly & 5 & $6.3 \%$ \\
\hline
\end{tabular}

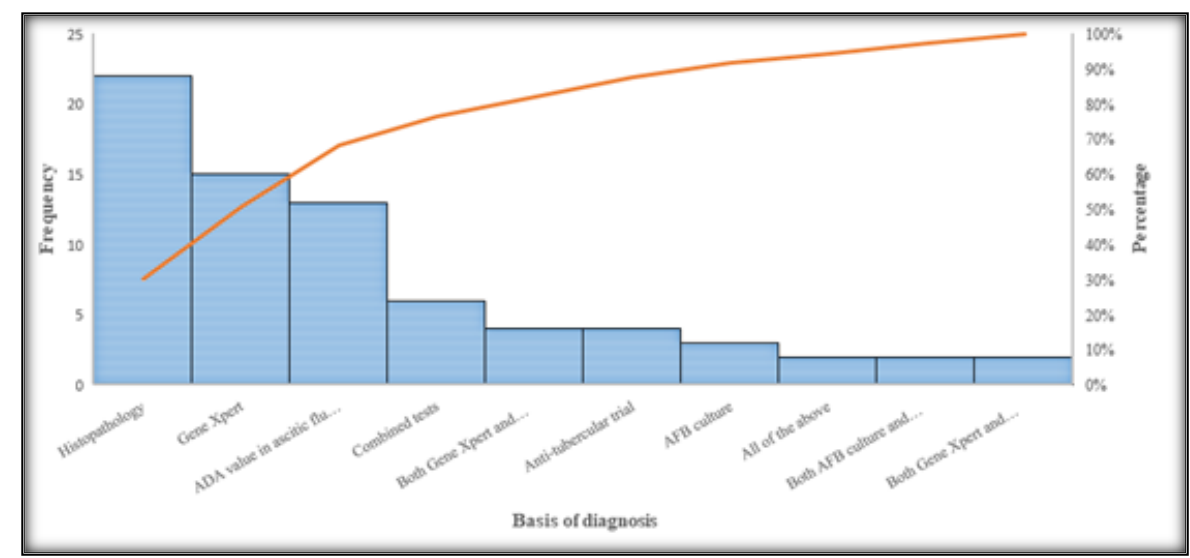

Figure 1: Basis of diagnosis of the study patients in abdominal tuberculosis in Bangladesh 
Annals of International Medical and Dental Research

E-ISSN: 2395-2822 | P-ISSN: 2395-2814

Vol-8, Issue-2 | March-April 2022

DOI: 10.53339/aimdr.2022.8.2.17

Page no- 120-127 | Section- Research Article (Gastroenterology)

[Figure 1] illustrates the basis of diagnosis in abdominal tuberculosis respondents in a tertiary care hospital in Bangladesh. Histolopathogy showed epithelioid cell granulomas with or without caseation in the maximum amount of patients (22) as well as Gene Xpert of tissue sample showed MTB DNA and ADA value in ascetic fluid (Cutoff $>40$ IU/L) exposedin 15 and 13 people, respectively. Besides this, positive AFB on the culture of tissue sample was found in 3 patients who reported undergoing drug susceptibility testing, two isolates were susceptible to all drugs (pan-susceptible), and only one showed resistance which is multidrug resistance (MDR TB).

\section{DISCUSSION}

Abdominal TB is a complex disease and has diverse symptomatology that is non-specific.[22] The most frequent presenting symptoms in this study were weight loss (96.9\%), abdominal pain $(75 \%)$, fever $(75 \%)$, loss of appetite $(68.8 \%)$, night sweats (34.4\%). This is relatively equal as compared to a previous study where the most frequent symptoms were abdominal pain $(93 \%)$, fever $(64 \%)$, night sweats $(48 \%)$, and weight loss (47\%).[22] Also, coinciding with the study result, abdominal pain and weight loss appeared to be the most frequent symptoms.[28] Moreover, the most frequent signs were anaemia $(34.4 \%)$, ascites $(27.9 \%)$, mass in the right lower quadrant $(18.8 \%)$, distension of the abdomen (12.6\%), abdominal lymphadenopathy $(9.3 \%)$, Oedema $(6.3 \%)$ and hepatomegaly (6.3\%). A study showed anemia in $70.4 \%$, ascites in $38.4 \%$, and mass in the right lower quadrant in $3.2 \%$ of patients. [29] This current study also shows the basis of diagnosis in abdominal tuberculosis were follows: histolopathogy showed epithelioid cell granulomas with or without caseation in the maximum amount of patients (22) as well as Gene Xpert of tissue sample showed MTB DNA and ADA value in ascitic fluid (Cutoff $>40$ IU/L) exposedin 15 and 13 people respectively. Besides these, good clinical response (based on weight gain and general improvement in wellbeing) to therapeutic trial anti-TB treatment in 4 patients. 6 patients were diagnosed based onthe combination of various tests (Histopathology, Gene Xpert, AFB culture, and ADA value in ascitic fluid). Among them, the basis of diagnosis of both Gene Xpert and histopathology were in only 4 patients, both AFB culture and histopathology were in just 2 patients, both Gene Xpert and ADA value in the ascitic fluid were in 2(2.74\%) patients, and combination of all tests (Histopathology, Gene Xpert, AFB culture and ADA value in ascitic fluid) was in $6(8.22 \%)$ patient. Basis of diagnosis in abdominal tuberculosis in a previous study were: histolopathogy showed epithelioid cell granulomas with or without caseation in $42 \%$ patients, Positive AFB on the culture ofa tissue sample in $2.9 \%$ patients, and good AFB on the culture of tissue sample clinical response to a therapeutic trial of anti-TB treatment in $2.3 \%$ patients. [22] Another study showed that $8.1 \%$ of patients responded positively to the anti-tubercular test.[27] In another literature, up to $40 \%$ of patients were given a therapeutic trial of anti-tuberculosis drugs.[30] Furthermore, positive AFB on the culture of tissue sample found in 3 patients report undergoing drug susceptibility testing. Two isolates were susceptible to all drugs (pansusceptible), and only one showed resistance, which is multidrug resistance (MDR-TB).A similar study showed that $16.39 \%$ of isolates 
Annals of International Medical and Dental Research

E-ISSN: 2395-2822 | P-ISSN: 2395-2814

Vol-8, Issue-2 | March-April 2022

DOI: 10.53339/aimdr.2022.8.2.17

Page no- 120-127 | Section- Research Article (Gastroenterology)

were susceptible to all drugs (pan-susceptible), and $5.4 \%$ of patients had MDR-TB. 27] Another similar type study showed $13 \%$ of patients had MDR-TB. [31]

\section{CONCLUSIONS}

Tuberculosis is a global public health issue that will continue to gain attention, owing to the AIDS pandemic and a lack of new effective treatments. Because of its drug resistance, it has become a global issue. In addition, Mycobacterium tuberculosis strains resistant to one or more first-line therapies are becoming increasingly common, resulting in highmortality outbreaks.[32,33,34,35,36] These issues highlight the necessity for speedy and accurate techniques for detecting resistant species. The availability of data on the gene alterations that causes antibiotic resistance will aid in achieving these objectives. Molecular

\section{REFERENCES}

1. Gupta I, Guin P. Communicable diseases in the South-East Asia Region of the World Health Organization: towards a more effective response. Bull World Health Organ. 2010;88(3):199-205. doi: 10.2471/BLT.09.065540.

2. Bloom BR, Murray CJ. Tuberculosis: commentary on a reemergent killer. Science. 1992;257(5073):1055-64. doi: 10.1126/science.257.5073.1055.

3. Cohn DL, Bustreo F, Raviglione MC. Drug-resistant tuberculosis: review of the worldwide situation and the WHO/IUATLD Global Surveillance Project. International Union Against Tuberculosis and Lung Disease. Clin Infect Dis. 1997;24 Suppl 1:S121-30. doi: 10.1093/clinids/24.supplement_1.s121. approaches have begun to transform drug susceptibility testing and identification by increasing sensitivity and speed. According to various studies, abdominal TB was usually identified in the third to a fourth decade, with a male majority, and had diverse and vague symptomatology. In all patients, no one test was sufficient to diagnose abdominal tuberculosis. For the diagnosis of ATB, a high index of clinical suspicion was necessary and the use of numerous adjuvant diagnostic methods. For the diagnosis of ATB, the diagnostic yield of several investigation methods was variable. The growth of Mycobacterium tuberculosis is an issue in both industrialized and developing countries, such as Bangladesh. There are few studies on abdominal TB in Bangladesh, and most of them are small case series. However, in Bangladesh, data on MDR-TB in pulmonary TB is available, but no data on MDR-TB in abdominal TB has been published.

4. Nguyen TNA, Anton-Le Berre V, Bañuls AL, Nguyen TVA. Molecular Diagnosis of DrugResistant Tuberculosis; A Literature Review. Front Microbiol. 2019;10:794. doi:10.3389/fmicb.2019.00794

5. Li J, Chung PH, Leung CLK, Nishikiori N, Chan EYY, Yeoh EK. The strategic framework of tuberculosis control and prevention in the elderly: a scoping review towards End TB targets. Infect Dis Poverty. 2017;6(1):70. doi:10.1186/s40249-017-0284-4

6. Zignol $M$, van Gemert $W$, Falzon $D$, et al. Surveillance of anti-tuberculosis drug resistance in the world: an updated analysis, 2007-2010. Bull World Health Organ. 2012;90(2):111-119D. doi:10.2471/BLT.11.092585

7. Huang TS, Tu HZ, Lee SS, Huang WK, Liu YC. Antimicrobial susceptibility testing of Mycobacterium tuberculosis to first-line drugs: comparisons of the MGIT 960 and BACTEC 460 systems. Ann Clin Lab Sci. 2002 Spring;32(2):142-7. 
Annals of International Medical and Dental Research E-ISSN: 2395-2822 | P-ISSN: 2395-2814

Vol-8, Issue-2 | March-April 2022

DOI: 10.53339/aimdr.2022.8.2.17

Page no- 120-127 | Section- Research Article (Gastroenterology)

8. Verma R, Khanna P, Mehta B. Revised national tuberculosis control program in India: the need to strengthen. Int J Prev Med. 2013;4(1):1-5.

9. Yam WC, Tam CM, Leung CC, et al. Direct detection of rifampin-resistant mycobacterium tuberculosis in respiratory specimens by PCR-DNA sequencing. J Clin Microbiol. 2004;42(10):4438-4443. doi:10.1128/JCM.42.10.4438-4443.2004

10. Mikhailovich VM, Lapa SA, Gryadunov DA, Strizhkov BN, Sobolev AY, Skotnikova OI, et al. Detection of rifampicin-resistant Mycobacteriumtuberculosis strains by hybridization and polymerase chain reaction on aspecialized TBmicrochip. Bull Exp Biol Med. 2001;131:94-98.

11. Rastogi N, Goh KS, David HL. Drug susceptibility testing in tuberculosis: a comparison of the proportion methods using Lowenstein-Jensen, Middlebrook 7H10 and 7H11 agar media and a radiometric method. Res Microbiol. 1989;140(6):40517. doi: 10.1016/0923-2508(89)90016-8.

12. Raviglione MC, Snider DE Jr, Kochi A. Global epidemiology of tuberculosis. Morbidity and mortality of a worldwide epidemic. JAMA. 1995;273(3):220-6.

13. Escalante P, Ramaswamy S, Sanabria H, Soini H, Pan $\mathrm{X}$, Valiente-Castillo O, Musser JM. Genotypic characterization of drug-resistant Mycobacterium tuberculosis isolates from Peru. Tuber Lung Dis. 1998;79(2):111-8. doi: 10.1054/tuld.1998.0013.

14. Musser JM. Antimicrobial agent resistance in mycobacteria: molecular genetic insights. Clin Microbiol Rev. 1995;8(4):496-514. doi: 10.1128/CMR.8.4.496.

15. Ramaswamy S, Musser JM. Molecular genetic basis of antimicrobial agent resistance in Mycobacterium tuberculosis: 1998 update. Tuber Lung Dis. 1998;79(1):3-29. doi: 10.1054/tuld.1998.0002.

16. Seung KJ, Keshavjee S, Rich ML. MultidrugResistant Tuberculosis and Extensively DrugResistant Tuberculosis. Cold Spring Harb Perspect Med. 2015;5(9):a017863. doi:10.1101/cshperspect.a017863

17. Cohn DL, Bustreo F, Raviglione MC. Drug-resistant tuberculosis: review of the worldwide situation and the WHO/IUATLD Global Surveillance Project. International Union Against Tuberculosis and Lung Disease. Clin Infect Dis. 1997;24 Suppl 1:S121-30. doi: 10.1093/clinids/24.supplement_1.s121.

PMID: 8994791.

18. Nagpaul DR. Multidrug resistance in tuberculosis. Indian J Tuberc. 1994;41:1-2.

19. Raviglione MC, Snider DE Jr, Kochi A. Global epidemiology of tuberculosis. Morbidity and mortality of a worldwide epidemic. JAMA. 1995;273(3):220-6.

20. Muralidhar S, Srivastava L. Evaluation of three methods to determine the antimicrobial susceptibility of Mycobacterium tuberculosis. Indian J Med Res. 2004;120(5):463-7.

21. Paramasivan $\mathrm{CN}$, Venkataraman $\mathrm{P}$, Chandrasekaran V, Bhat S, Narayanan PR. Surveillance of drug resistance in tuberculosis in two districts of South India. Int J Tuberc Lung Dis. 2002;6(6):479-84. doi: 10.5588/09640569512977.

22. Khan R, Abid S, Jafri W, Abbas Z, Hameed K, Ahmad Z. Diagnostic dilemma of abdominal tuberculosis in non-HIV patients: an ongoing challenge for physicians. World J Gastroenterol. 2006;12(39):6371-5. doi: 10.3748/wjg.v12.i39.6371.

23. Lamy $B$, Dargère $S$, Arendrup MC, Parienti JJ, Tattevin P. How to Optimize the Use of Blood Cultures for the Diagnosis of Bloodstream Infections? A State-of-the Art. Front Microbiol. 2016;7:697. doi:10.3389/fmicb.2016.00697

24. Dwivedi M, Misra SP, Misra V, Kumar R. Value of adenosine deaminase estimation in the diagnosis of tuberculous ascites. Am J Gastroenterol. 1990;85(9):1123-5.

25. Bhargava DK, Shriniwas, Chopra P, Nijhawan S, Dasarathy S, Kushwaha AK. Peritoneal tuberculosis: laparoscopic patterns and its diagnostic accuracy. Am J Gastroenterol. 1992;87(1):109-12.

26. Bhargava DK, Tandon HD, Chawla TC, Shriniwas, Tandon BN, Kapur BM. Diagnosis of ileocecal and colonic tuberculosis by colonoscopy. Gastrointest Endosc. 1985;31(2):68-70. doi: 10.1016/s00165107(85)71995-5.

27. Kapoor VK. Abdominal tuberculosis. Postgrad Med J. 1998;74(874):459-467. doi:10.1136/pgmj.74.874.459

28. Samant H, Desai D, Abraham P, Joshi A, Gupta T, Rodrigues C, George S. Acid-fast bacilli culture positivity and drug resistance in abdominal tuberculosis in Mumbai, India. Indian J Gastroenterol. 2014;33(5):414-9. doi: 10.1007/s12664014-0467-x. 
Annals of International Medical and Dental Research

E-ISSN: 2395-2822 | P-ISSN: 2395-2814

Vol-8, Issue-2 | March-April 2022

DOI: 10.53339/aimdr.2022.8.2.17

Page no- 120-127 | Section- Research Article (Gastroenterology)

29. Vadwai V, Boehme C, Nabeta P, Shetty A, Alland D, Rodrigues C. Xpert MTB/RIF: a new pillar in diagnosis of extrapulmonary tuberculosis? J Clin Microbiol. 2011;49(7):2540-5. doi: 10.1128/JCM.02319-10.

30. Uygur-Bayramicli O, Dabak G, Dabak R. A clinical dilemma: abdominal tuberculosis. World J Gastroenterol. 2003;9(5):1098-101. doi: 10.3748/wjg.v9.i5.1098.

31. Lin PY, Wang JY, Hsueh PR, Lee LN, Hsiao CH, Yu $\mathrm{CJ}$, Yang PC. Lower gastrointestinal tract tuberculosis: an important but neglected disease. Int J Colorectal Dis. 2009;24(10):1175-80. doi: 10.1007/s00384-009-0721-3.

32. Bifani PJ, Plikaytis BB, Kapur V, Stockbauer K, Pan $X$, Lutfey ML, et al. Origin and interstate spread of a New York City multidrug-resistant Mycobacterium tuberculosis clone family. JAMA. 1996;275(6):452-7.

33. Blázquez J, Espinosa de Los Monteros LE, Samper S, et al. Genetic characterization of multidrug-resistant Mycobacterium bovis strains from a hospital outbreak involving human immunodeficiency viruspositive patients [published correction appears in J Clin Microbiol 1998 Aug;36(8):2398]. J Clin
Microbiol.

1997;35(6):1390-1393.

doi:10.1128/jcm.35.6.1390-1393.1997

34. Edlin BR, Tokars JI, Grieco MH, Crawford JT, Williams J, Sordillo EM, et al. An outbreak of multidrug-resistant tuberculosis among hospitalized patients with the acquired immunodeficiency syndrome. $\mathrm{N}$ Engl J Med. 1992;326(23):1514-21. doi: 10.1056/NEJM199206043262302.

35. Frieden TR, Sherman LF, Maw KL, Fujiwara PI, Crawford JT, Nivin B, et al. A multi-institutional outbreak of highly drug-resistant tuberculosis: epidemiology and clinical outcomes. JAMA. 1996;276(15):1229-35.

36. Ritacco V, Di Lonardo M, Reniero A, Ambroggi M, Barrera L, Dambrosi A, et al. Nosocomial spread of human immunodeficiency virus-related multidrugresistant tuberculosis in Buenos Aires. J Infect Dis. 1997;176(3):637-42. doi: 10.1086/514084.

Source of Support: Nil, Conflict of Interest: None declared 